\title{
Well-defined Copper(I) Complexes for Click Azide-Alkyne Cycloaddition Reactions: One Click Beyond
}

\author{
Silvia Díez-González* \\ Department of Chemistry, Imperial College London \\ Exhibition Road, South Kensington, SW7 2AZ London (UK) \\ s.diez-gonzalez@imperial.ac.uk
}

\begin{abstract}
:
The discovery of copper(I) species as excellent catalysts for the regioselective cycloaddition reactions of azides and alkynes served as proof-of-concept of the importance of Click chemistry and opened a broad field of research that has found numerous ramifications in biochemistry, materials and medicinal science, for instance. The use of ligands in this context not only serves to stabilize the oxidation state of copper, but has also been shown to increase and modulate its reactivity. Still, efforts focused on developing more efficient catalytic systems for this transformation remain limited. Herein, the catalytic activities of ligated copper systems are reviewed in a way intended inspirational for further developments.
\end{abstract}

\section{Introduction}

Transition metal catalysis is one of the most powerful tools available to chemists for the development of cleaner and more sustainable processes. Although simple metal salts can mediate a number of transformations, it was the use of ligands that catapulted organometallic catalysis to its present leading status. In particular, the use of well-defined complexes allows for a better control of the nature of the species present in the reaction media and generally avoids the need for excess of ligand and/or reagents for achieving optimal catalytic performance. These two points are crucial in the continuous quest of molecular chemistry for more efficient and less contaminating processes capable of providing diverse and complex architectures.

In 2001, Sharpless and co-workers coined the concept of Click Chemistry. ${ }^{1}$ Inspired by Nature, they proposed to gather most synthetic efforts around a few transformations with a strong thermodynamic driving force in order to prepare more complex products from a set of building blocks. Most common carbon-heteroatom bond forming reactions could be considered Click if they fulfilled a number of basic requirements: no sensitivity towards moisture or oxygen, high yields and stereospecifity, absence of solvent (or use of a benign one) and simple product isolation. 
1,3-Dipolar cycloadditions (Huisgen reactions) ${ }^{2}$ are one of the most general approaches for the preparation of five-membered heterocycles. During his studies on azidocumulenes, L'abbé first observed a copper(I)-catalyzed [3+2] cycloaddition reaction in $1984 .{ }^{3}$ However, this reactivity was overlooked until 2002, when Sharpless ${ }^{4}$ and Meldal $^{5}$ reported independently the efficiency of copper(I) species as catalysts for the cycloaddition of azides and terminal alkynes to yield 1,2,3triazoles (Scheme 1). Outstandingly, under such conditions, the reactions were completely regioselective and only 1,4-disubstituted triazoles were formed, in contrast with the mixture of regioisomers normally obtained under classical thermal conditions. Since, this copper-catalyzed azide-alkyne cycloaddition $(\mathrm{CuAAC})$ has become the most popular Click reaction developed to date.

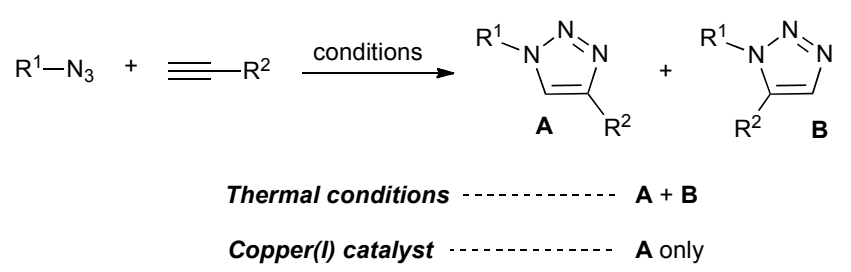

Scheme 1. 1,2,3-Triazoles synthesis.

Early mechanistic studies led to the proposal of the stepwise catalytic cycle depicted in Scheme $2 .^{6}$ In a first stage, a newly formed acetylide-copper complex would interact with the azide, activating it toward nucleophilic attack of the acetylide carbon to the 'end' nitrogen atom of the azide. Subsequent ring contraction of the generated metallacycle would lead to a copper-triazolide, direct precursor of the reaction product upon protonation.

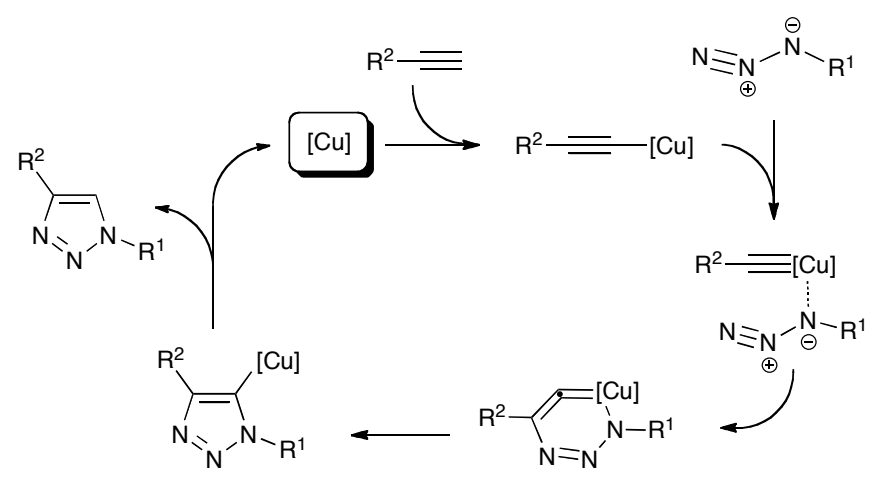

Scheme 2. Early proposed mechanism for the CuAAC.

Further studies showed that in most cases, the reaction is second order in copper, probably due to the dynamic equilibrium of different copper-acetylides existing in solution. In fact, there is increasing evidence favoring bi- or polynuclear pathways for this reaction. ${ }^{7}$

Independently of its mechanism, this reaction has attracted an enormous interest and its applications are still increasing exponentially. Although it is possible to prepare [1,2,3]-triazoles under metal-free conditions, these usually require heat and provide a very limited regioselectivity (traditional Huisgen reactions), or are very limited in scope, such as the cycloaddition reactions 
with cyclooctyne derivatives. ${ }^{8}$ So far, only copper catalysis has provided a Click approach to the preparation of 1,4-disubstituted triazoles. ${ }^{9}$ Due to the known instability of numerous copper(I) species, the active species are often generated in situ from a copper(II) salt and a reducing agent (more than often sodium ascorbate). These systems can be extremely efficient, but they are intrinsically limited to water-tolerant substrates and only marginal leeway is left for unsuccessful reactions. Alternatively, the addition of ligands can not only protect $\mathrm{Cu}^{\mathrm{I}}$ centers, but also greatly improve their activity, allowing for smoother reaction conditions or broader applicability. Preformed catalysts are still scarcely used in this transformation and the families of ligands studied so far possess very distinct stereoelectronic properties, which makes it even more difficult to understand the mechanistic picture for this transformation. Furthermore, the reports comparing different families of ligands remain scarce. ${ }^{10}$

This Perspective provides a comprehensive overview of the activity of ligated copper(I) species in the cycloaddition of azides and alkynes, with a focus on well-defined copper catalysts. Even if application examples of the discussed catalytic systems might be mentioned, it is out of the scope of this review to comment them all and for this purpose, the reader should refer to one of the plethora of reviews available. ${ }^{11}$ Instead, this Perspective will focus on the particularities of each catalytic system, their adjustment to the Click criteria. The advantages of using ligated species for the use of a larger variety of starting materials and for the preparation of fully substituted triazoles will be specifically discussed.

\section{Copper(I)-Catalyzed Reactions of Organic Azides and Terminal Alkynes}

Nitrogen containing ligands have been the first and the most popular ligands for CuAAC. In numerous applications the $\mathrm{N}$-containing additive is merely referred to as a base, even though their affinity for copper is well-known. Alternatively, such additives increase the solubility of copper(I) species in the reaction media. Despite the plethora of applications these ligands have found to date, the nature of the actual active catalyst has scarcely been studied, leaving plenty of room for further investigation and improvements.

\subsection{Nitrogen Ligands}

\subsubsection{Amine ligands}

Tertiary amines have been used as bases and/or ligands in CuAAC reactions, often combined with more strongly coordinating ligands, although they can be the only additives in the reaction media. Simple triethylamine is capable of stabilizing the copper(I) active species even in reactions carried out 'on water'. ${ }^{12}$ Other readily available amines have been employed (Figure 1$),{ }^{13}$ but regrettably, no studies on the influence of the substituents on the nitrogen atom are available to date. The most 
popular amine of this series is the Hünig's base, diisopropylethylamine (DIPEA). Not only it was the first ligand applied to this transformation -already used in the original report by Meldal et al. -5 but also it has become a well-established Click protocol.

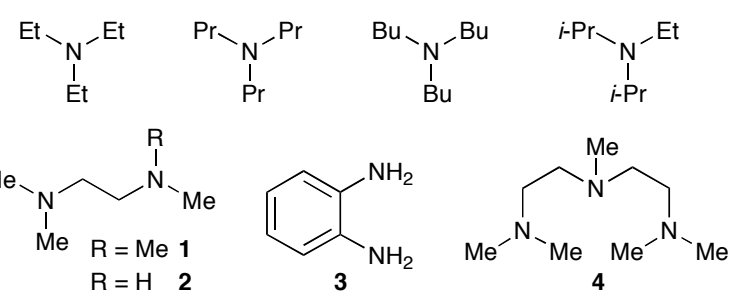

Figure 1. Amines used in CuAAC.

Diamine ligands have also been employed in $\mathrm{CuAAC}$, such as 2, applied to the functionalization of polypeptides, ${ }^{14}$ or 1,2-phenylenediamine 3, which showed a remarkable activity for the cycloaddition of different alkynes and glucosyl azides in water. ${ }^{15}$

On the other hand, a triamine ligand, $N, N$ ', $N$ ''-pentamethylethylenetriamine 4 (PMDETA) is probably the most commonly employed ligand in CuAAC, due to the well-established efficiency of $\mathrm{CuBr} / \mathrm{PMDETA}$ in polymerization processes such as ATRP. A solid supported version on this catalytic system, based on poly(ethyleneimine), was recently reported. ${ }^{16}$ However, it displayed a gradual decrease in activity when reused either because of oxidation of the copper(I) centers or metal leaching. Better results were obtained with related complex $\mathbf{5},{ }^{17}$ bearing a crowded tripodal ligand to effectively protect the copper center against oxidation while keeping it highly active. This catalyst respected all Click requirements and in particular, solubility of $\mathbf{5}$ in the hydrocarbon solvents allowed for its separation from the reaction products by simple filtration. The separated filtrate could be reloaded with the starting azide and alkyne for a second reaction, whereas the separated triazoles showed only negligible copper contamination. The extremely high reactivity of this complex was illustrated by its application to the preparation triazoles-linked dendrimers. Stoichiometric amounts of catalyst are generally required for the later application, since copper might be trapped inside the formed dendrimer. Nevertheless, only $0.1 \mathrm{~mol} \%$ of 5 was enough to produce a dendrimer in good yield from a nona-azide. Furthermore, $\mathbf{5}$ was found superior to other reported catalysts for $\mathrm{CuAAC}$ in the functionalization of polyhedral oligosilsesquioxane. ${ }^{18} \mathrm{~A}$ related all-methyl ligand has also been employed in the preparation of different macromolecules. ${ }^{19}$

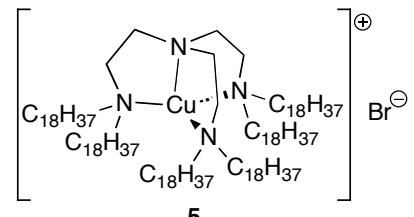

2.2.2. $N\left(s p^{2}\right)$-Type Ligands 
The first simple imine ligands applied to the Huisgen cycloaddition were pyridylimines 6 (Figure 2). ${ }^{20}$ These ligands showed a remarkable activity when used in one pot CuAAC/living radical polymerizations, both reactions proceeding simultaneously rather than sequentially. ${ }^{21}$ One important drawback of these additives is their inherent instability (they must be kept at $0^{\circ} \mathrm{C}$ under inert atmosphere) which preclude their use under Click-suitable conditions, at least when the coordinated copper species are generated in situ. Alternatively, stable pybox derivative 7 was applied to the kinetic resolution of racemic azides through their cycloaddition with a terminal alkyne. $^{22}$

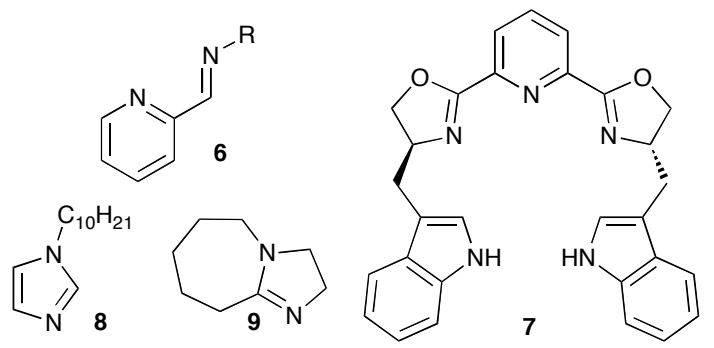

Figure 2. Imine ligands used in CuAAC reactions.

Imidazole derivatives have also been applied to CuAAC. Very recently, it was reported that the presence of a long aliphatic chain on the imidazole ring was essential to ensure the acceleration of the reaction. ${ }^{23}$ In the presence of imidazole $\mathbf{8}$, different triazoles (including very hindered ones) could be prepared with $0.5 \mathrm{~mol} \% \mathrm{CuI}$ on water or under neat conditions. The obtained yields were excellent, but some of the reaction products had to be purified on silica gel. Other cyclic imines studied in this context include the commercially available 1,8-diazabicycloundec-7-ene 9 (DBU). ${ }^{24}$ Despite its availability, no methodological studies have been carried out with this ligand, maybe due to its high toxicity, incompatible with proper Click reactions. A related triazabicyclodecene scaffold has also been reported for the polymer-supported $\mathrm{CuAAC}{ }^{25}$

Undoubtedly, the most commonly used cyclic imine-type ligands used in the cycloaddition of azides and alkynes are polytriazoles. As early as 2003, and alerted by the observation of accelerating reaction rates in their preparation, the biocompatibility of this transformation using polytriazoles as ligands was demonstrated. ${ }^{26}$ Since, the exponentially increasing applications of these ligands have been particularly focused, on biological systems and protein labeling in particular. Even if sodium ascorbate can still be used as reducing agent in these sensitive applications, tris(carboxyethyl)phosphine is a much more popular reductant in this context thanks to its softness and ability to protect certain aminoacids residues in proteins from oxidative coupling.

One year after the first application of polytriazoles as additives in CuAAC, a comparative study of different architectures was reported. ${ }^{27}$ Different mono, bis and tris-triazoles were screened along with simple amines, diamines and pyridine derivatives. Remarkably, very different trends in 
reactivity were observed depending on the nature of the copper source; whereas amino-triazole $\mathbf{1 0}$ was the most competent ligand for $\mathrm{CuSO}_{4} / \mathrm{NaAsc}$ system, bis-triazole 11 was the best performing with $\left[\mathrm{Cu}\left(\mathrm{NCMe}_{4}\right] \mathrm{PF}_{6}\right.$ (Figure 3). Tris(benzyltriazolylmethyl)amine (TBTA) 12 was also a good ligand for the model reaction, although in a lesser extent ( $84 \%$ yield $v s 94 \%$ with 11). Still, tristriazoles, and TBTA in particular, have virtually become the only triazoles used as ligands in CuAAC. A polymer-supported version of $\mathrm{TBTA} / \mathrm{CuPF}_{6}$ has also been reported. ${ }^{28}$ This is one of the few pre-isolated copper(I)-triazole species applied to this reaction, ${ }^{29}$ the coordination mode of the ligand to the copper center was not investigated, though. $1 \mathrm{~mol} \%[\mathrm{Cu}]$ of this resin could be reused ten consecutive times without a significant drop in activity, although long reaction times (up to 2 days) were required to ensure high yields.
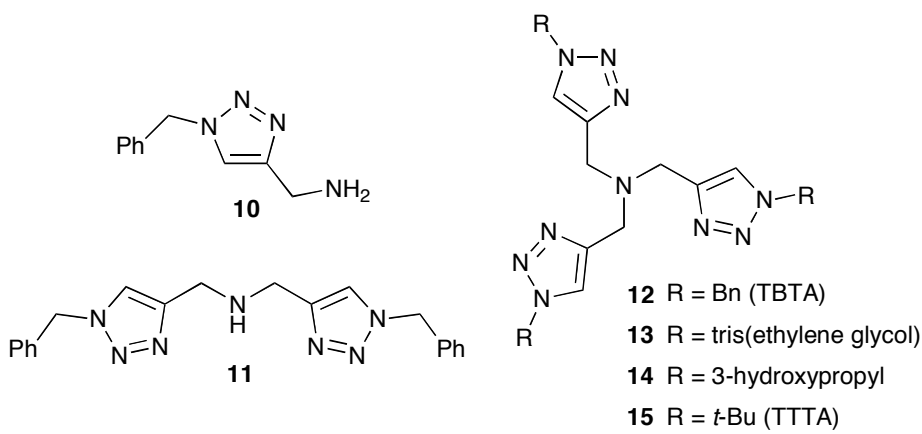

Figure 3. Triazole ligands in CuAAC.

Water-soluble triazoles such as $\mathbf{1 3}^{30}$ and $\mathbf{1 4}^{31}$ were also studied for different applications, and $\mathbf{1 3}$ in particular was shown to actively protect histidine residues in proteins against reactive oxygenated species in the reaction media. ${ }^{32}$ In this example, since $\mathbf{1 3}$ is actually oxidized, an excess of ligand had to be employed.

The preparation of 16, a well-defined copper(I) complex with TBTA 12, notably established that (at least in the solid state) no metal coordination with the tertiary amine moiety takes place. ${ }^{33}$ This air-sensitive compound displayed an unusual dinuclear structure with two copper centers in a distorted tetrahedral geometry bridged by two triazole units through their medial and proximal nitrogen atoms (Figure 4). When using 16 as catalyst, a model reaction displayed a first order dependence on the copper concentration, pointing towards $\mathbf{1 6}$ as a precursor of the actual active catalytic species and no further catalytic studies were reported.
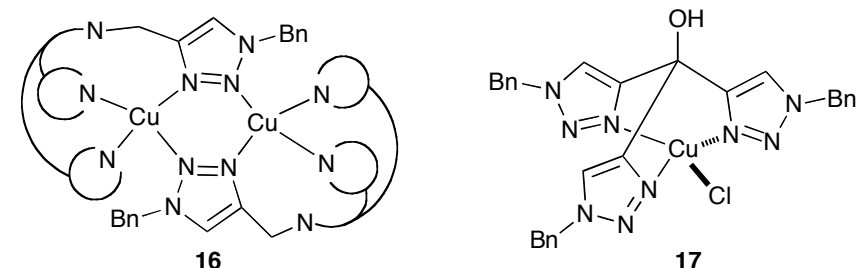

Figure 4. Triazoles-copper(I) complexes in CuAAC. 
Better catalytic performance was observed with related air stable tris(triazolyl)methane complex $17,{ }^{34}$ and a variety of triazoles could be efficiently prepared from the corresponding azides $(0.5$ mol \% $[\mathrm{Cu}]$, water or neat, RT). As drawbacks, the presence of free amines in the starting materials drastically reduced the reaction conversion, and the structure shown in Figure 4 was proposed based on the characterization data of a copper(II) analogue, although no crystals could be grown for 17.

Diverse structures related to TBTA 12 have been examined in CuAAC (Figure 5). ${ }^{35}$ Notably, the most performing ligands were different depending on the reaction conditions. Hence, whereas 18 displayed a good activity in a range of $\mathrm{pH}$ values under diluted biocompatible concentration, 19 and 20 were optimal for concentrated conditions. Furthermore, despite their similar structure, the best ratio metal/ligand changed from $1: 1$ for $\mathbf{1 9}$ to $2: 1$ for $\mathbf{2 0}$. Also, 21, a more strongly coordinating ligand, was found better performing although it can lead to catalyst deactivation at high ligand/metal ratios. Such deactivation can be reversed using strongly coordinating solvents (DMSO or $N$-methylpyrrolidinone) or a high alkyne concentration. All these observations, along with the different kinetic data obtained according to the reaction conditions, reflect a very complicated mechanistic picture for these systems. It seems reasonable that the relatively weak chelating properties of these ligands, combined with the diverse copper coordination chemistry make such studies even more complicated and that the rate-limiting step may differ easily depending on the reaction conditions.
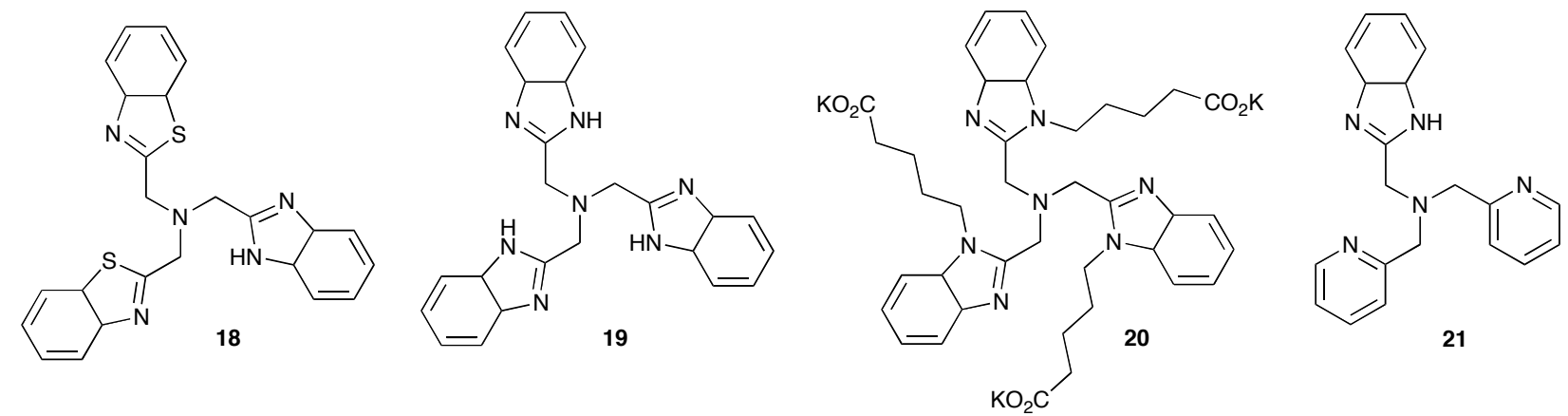

Figure 5. Benzimidazole/benzothiazole ligands for $\mathrm{CuAAC}$.

Pyridine derivatives have also been investigated in CuAAC. Noteworthy, simple pyridine was essential to ensure clean CuAAC from propargyl carbamates (Scheme 3), where a mixture of products was unexpectedly obtained when the cycloaddition reaction was attempted with $\mathrm{CuSO}_{4} / \mathrm{NaAsc}^{36}$ The authors rationalized that in this case, the postulated triazolide intermediate would be further coordinated with pyridine molecules, preventing the interaction of the copper center with the carbonyl group from the carbamate. Such interaction would weaken the $\mathrm{C}-\mathrm{O}$ bond of the molecule, thus facilitating the cleavage of the carbamate function and leading to the formation of by-products. 


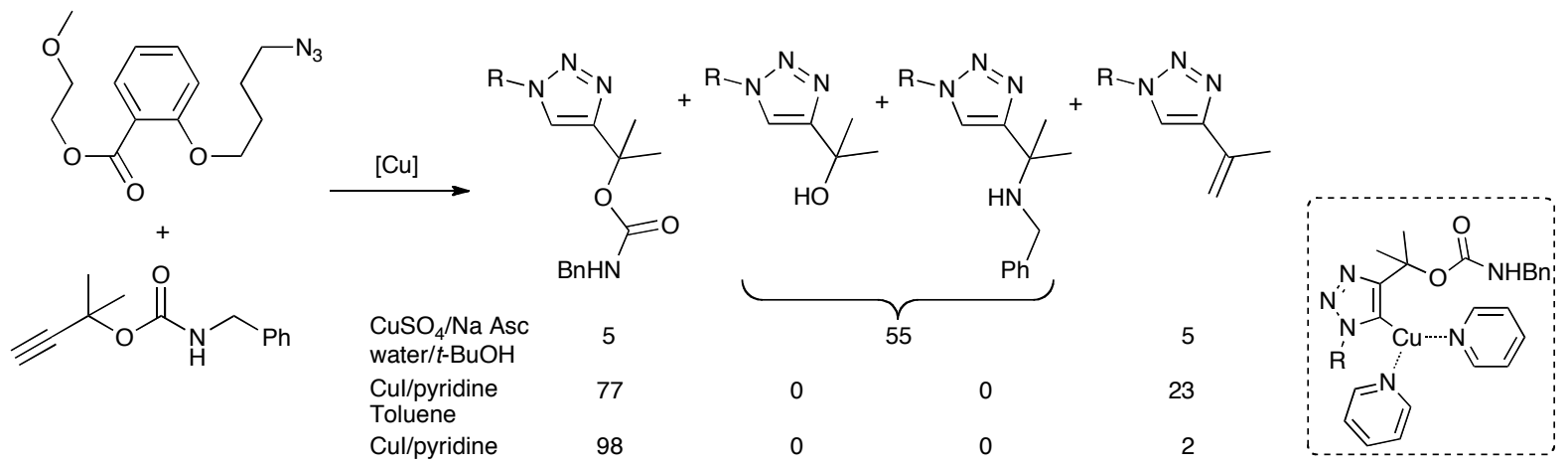

Scheme 3. Selectivity for CuAAC with propargyl carbamates.

Other reported pyridine derivatives are shown in Figure 6. Lutidine $\mathbf{2 2}$ is a popular one and it has notably been used as the only additive in the functionalization of DNA, ${ }^{37}$ human growth hormone $^{38}$ or in the stabilization of organogels. ${ }^{19 a}$ Alternatively, bipyridine $\mathbf{2 3}$ and phenanthroline derivatives were found remarkable ligands quite early thanks to a fluorescence quenching assay, ${ }^{39}$ and have been used in several applications, particularly in macromolecular science. The nature of the active species in these applications remains elusive, since the copper/ligand ratios employed vary from $\mathrm{Cu}: \mathrm{L}=1: 3$ to $2: 1$. Sulfonated bathophenanthroline $\mathbf{2 4}$ has mainly been applied to the functionalization of biomolecules, where it proved superior to standard TBTA 12 in some applications, ${ }^{40}$ and remains one of the most accelerating ligands known for bioconjugation.

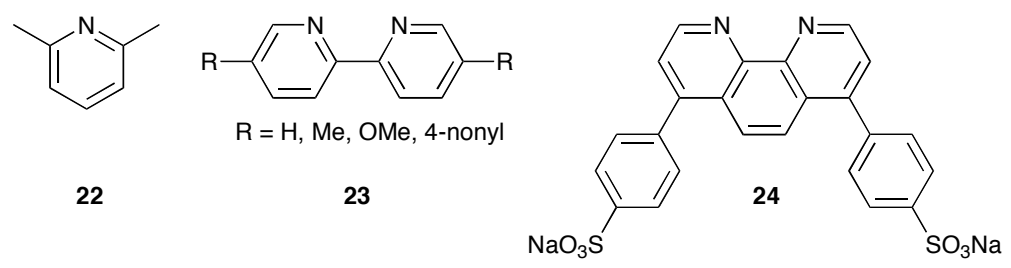

Figure 6. Pyridine derivatives for CuAAC.

Another phenanthroline derivative was found optimal for the activity in CuAAC of biopolymer supported catalyst 25 (Eq 1). ${ }^{41}$ Remarkably, the supported copper(I) complex was more active than its homogeneous analogue. Reactions were carried out in ethanol or water with only $0.1 \mathrm{~mol} \%$ $[\mathrm{Cu}]$ at $70^{\circ} \mathrm{C}$ to obtain the expected triazoles in high yields after simple filtration or recrystallization.

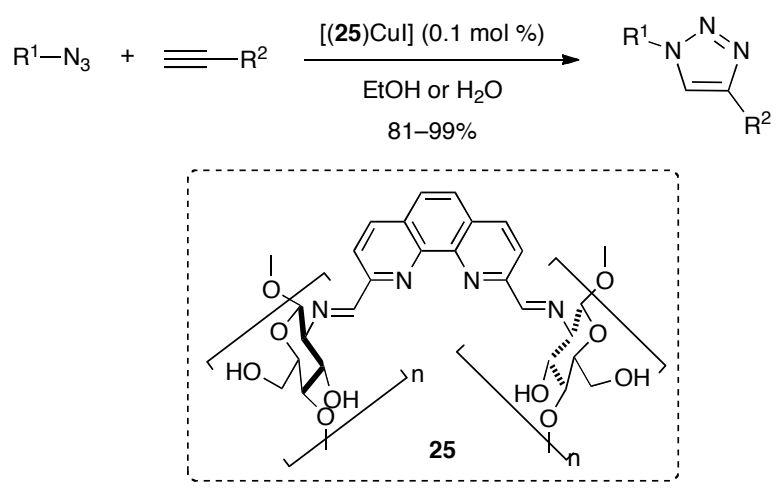


Finally, the accelerating effect of chelation has also been observed with certain functionalized azides. ${ }^{42}$ Pyridine containing azides were particularly reactive in CuAAC in the presence of $\mathrm{Cu}(\mathrm{OAc})_{2} / t-\mathrm{BuOH},{ }^{43}$ although amine, carboxylic acid, ether and thioether groups also increased the reaction rates.

\subsection{Phosphorous Ligands}

Omnipresent in organometallic catalysis, it is not surprising that phosphorous containing ligands were the first ligands applied to the cycloaddition of azides and alkynes. In 2003, only one year after the discovery of copper(I) species as catalysts for azide-alkyne cycloadditions, $\left[\mathrm{CuBr}\left(\mathrm{PPh}_{3}\right)_{3}\right]$ 26 and $\left\{\mathrm{CuI}\left[\mathrm{P}(\mathrm{OEt})_{3}\right]\right\} \mathbf{2 7}$ complexes were applied to the preparation of various glyco-derived triazoles in good yields. ${ }^{44}$ These two complexes were selected because they were known in the literature and soluble in organic solvents, which allowed for homogeneous reactions desirable for certain applications. Reactions were run under microwave irradiation in the presence of an organic base (DIPEA or DBU for the most difficult substrates), which can also be regarded as competitive ligands for the copper center. Even if no results on the absence of such additives were reported in the original study, these conditions have been widely used in diverse applications such as macromolecular science. Specifically, the above-mentioned complexes have been considered the catalysts of choice for the preparation of more delicate glycopolymers ${ }^{45}$ and oligomers ${ }^{46}$ or biologically active molecules. ${ }^{47}$ In all precedent applications a base (most often DIPEA) was employed, however, such additives were not always required. ${ }^{48}$

A recent methodological study showed that the constraining reaction conditions reported in the original study are not required in most cases. Hence, $\left[\mathrm{CuBr}\left(\mathrm{PPh}_{3}\right)_{3}\right] \mathbf{2 6}$ was a performing catalyst when using $0.5 \mathrm{~mol} \%$ under neat or aqueous conditions at room temperature and in the absence of any other additive (Scheme 4). ${ }^{49}$ In all cases, the corresponding triazoles were recovered in pure form after simple filtration or extraction, although higher copper loadings ( 2 mol \%) and/or toluene as solvent were required for the reaction of some glyco-derivatives.

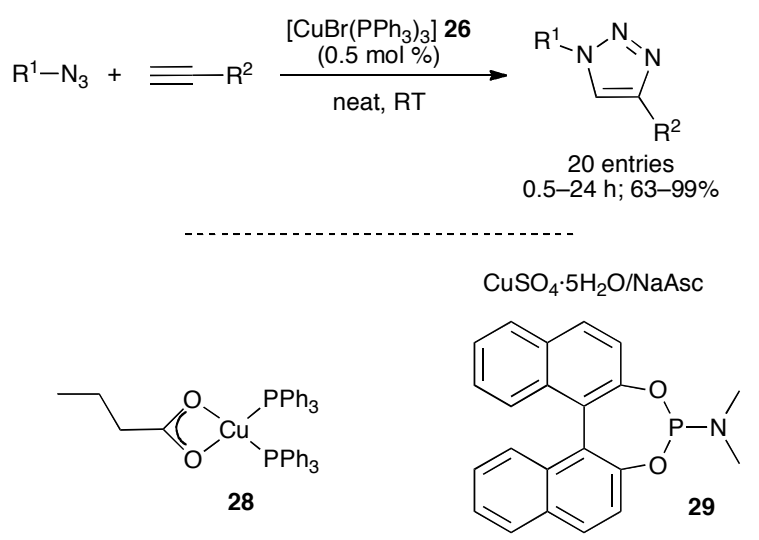

Scheme 4. $P$-Ligand/copper(I)-mediated CuAAC. 
Despite the popularity of phosphorus-based ligands in modern chemistry, to date, only two other studies are available so far. Triphenylphosphine was shown to greatly improve the catalytic activity of various copper carboxylate complexes, better than other common phosphorous ligands such as $\mathrm{PCy}_{3}$, BINAP or dppe. ${ }^{50} \mathrm{PPh}_{3}$ was postulated to improve the solubility of the catalyst in the reaction solvent, DCM, although neat conditions allowed for lower copper loadings. Reactions were carried out at room temperature in air with only $0.15-0.05 \mathrm{~mol} \%$ of catalyst 28 , although some of the obtained triazoles required purification on silica gel (Scheme 4).

Phosphoramidite ligands have also been reported to accelerate CuAAC. ${ }^{51}$ The active copper(I) species were generated in situ from $\mathrm{CuSO}_{4} \cdot 5 \mathrm{H}_{2} \mathrm{O}$ and sodium ascorbate in the presence of MonoPhos 29, although higher copper loadings (1 mol \%) and purification on column chromatography were required with this catalytic system.

\subsection{Carbon Ligands}

$\mathrm{N}-$ Heterocyclic carbene (NHC) ligands have displayed a remarkable activity in CuAAC. $[\mathrm{CuBr}$ (SIMes)] 30 was the first NHC-containing complex reported for this reaction, with $0.8 \mathrm{~mol}$ $\%$ of 30, diverse triazoles were prepared in aqueous media or under neat conditions and isolated after filtration or extraction (Scheme 5). ${ }^{52}$ The main drawback of this catalyst is that sluggish reactions were often obtained with oily/low-melting products. A more comprehensive screening of complexes later identified [CuI(IAd)] $\mathbf{3 1}$ as an improved catalyst, which also showed a better tolerance towards steric hindrance and functional groups. ${ }^{53}$

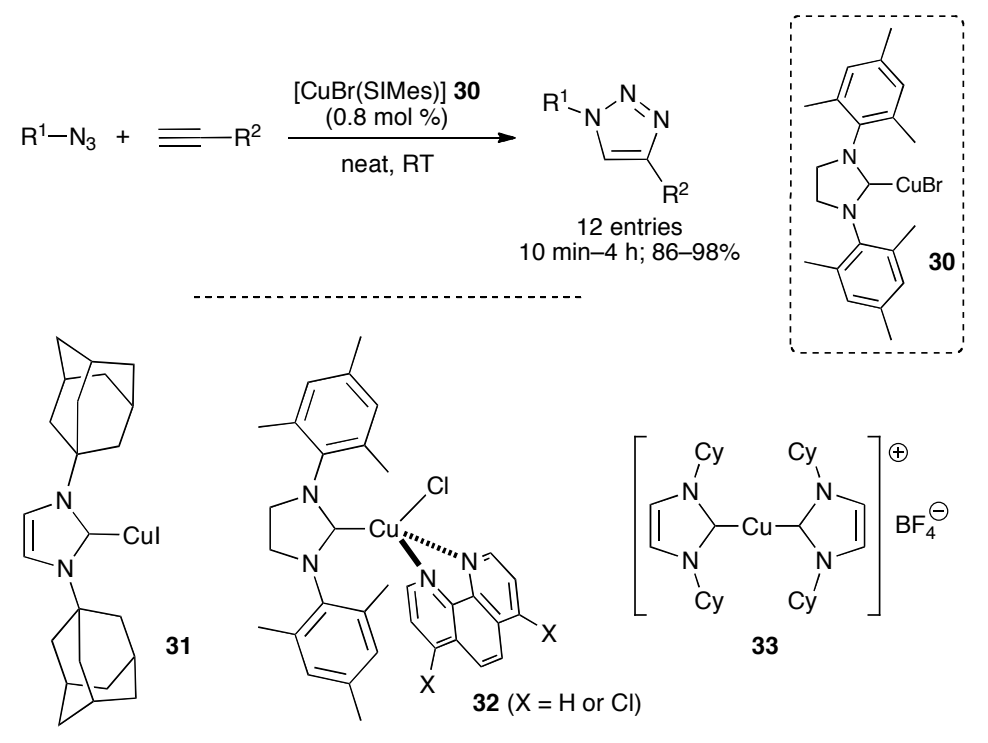

Scheme 5. $[\mathrm{Cu}(\mathrm{NHC})]-$ mediated $\mathrm{CuAAC}$.

Several modifications to the original catalyst $\mathbf{3 0}$ can be found in the literature. Blechert and Buchmeiser reported that polymer-bound version of $\mathbf{3 0}$ led to the formation of the expected triazoles when using only $0.2 \mathrm{~mol} \%[\mathrm{Cu}]$ at room temperature in a mixture $\mathrm{THF} /$ water. $^{54}$ 
However, only moderate yields (up to $75 \%$ ) were obtained after overnight reactions and the crude products were filtered on silica prior recrystallization. On the other hand, aromatic nitrogen donor ligands have been reported to further improve the catalytic activity of [CuX(NHC)] complexes. ${ }^{55}$ Phenanthroline derivatives displayed a notable effect and the corresponding adducts 32 could be isolated and characterized. The copper centers in $\mathbf{3 2}$ have a distorted tetrahedral environment instead of the linear arrangement in $[\mathrm{CuX}(\mathrm{NHC})]-$, and the copper-chlorine bonds are elongated when compared to the parent $[\mathrm{CuCl}(\mathrm{SIMes})]$. These particular features were proposed to account for the observed accelerated rates. However, a direct comparison of these results with the ones reported with 30 cannot be drawn, since not only the halogen $(\mathrm{Cl}$ instead of $\mathrm{Br})$, but also the solvent used ( $t$-BuOH/water or EtOH instead of pure water) were different in both studies.

In contrast with the catalytic systems bearing N-containing ligands, most efforts with NHCcontaining ligands have been focus on methodological advances, instead of on their application to more complex systems. Nevertheless, $[\mathrm{CuX}(\mathrm{NHC})]$ species have already been used as latent catalysts, ${ }^{56}$ or for the preparation of triazoles containing porphyrins, ${ }^{57}$ carbanucleosides, ${ }^{58}$ or chelators for platinum or palladium-based potential anticancer drugs. ${ }^{59}$ Moreover, the presence of an NHC ligand on a copper center allowed for the isolation and characterization of a coppertriazolide derivative, one of the postulated intermediates in the reaction mechanism. ${ }^{60}$

A second family of $[\mathrm{Cu}(\mathrm{NHC})]$ complexes, of general formulae $\left[\mathrm{Cu}(\mathrm{NHC})_{2}\right] \mathrm{X}$, has also been studied. ${ }^{61}$ Catalyst 33 (Scheme 5) led to excellent yields with $0.5 \mathrm{~mol} \%[\mathrm{Cu}]$ at room temperature in $\mathrm{MeCN}$ or under neat conditions. The most remarkable feature of this catalyst is that it allowed for catalyst loadings down to ppm level in the formation of several triazoles, leading to unprecedented TON and TOF values of over 20000 and $5000 \mathrm{~h}^{-1}$, respectively. Mechanistic studies on this catalytic system showed that whereas there was no interaction between $\mathbf{3 3}$ and organic azides, the catalyst was fully converted in minutes in the presence of a terminal alkyne. The corresponding azolium salt, $\mathrm{ICy} \cdot \mathrm{HPF}_{6}$, could be isolated along with a copper acetylide (Scheme 6). These results would imply that one of the NHC ligands originally on the copper center could act as a base, deprotonating the alkyne to initiate the catalytic cycle. This would be then closed by the delivery of a proton to a triazolide intermediate by the azolium salt.

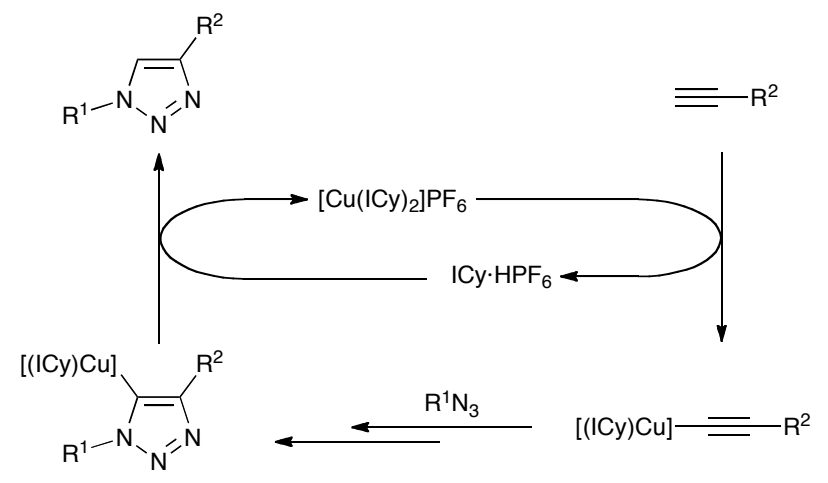


Scheme 6. Mechanistic proposal for $\left[\mathrm{Cu}(\mathrm{NHC})_{2}\right] \mathrm{X}$ complexes.

Finally, it is important to note that different studies on cycloaddition reactions of azides and alkynes have been carried out in imidazolium-based ionic liquids. ${ }^{62}$ Even if the formation of a NHC-copper complex with the reaction media was not evoked, it cannot be ruled out neither, particularly in the presence of a base.

\subsection{Oxygen Ligands}

Oxygen-based ligands have scarcely been investigated in CuAAC reactions, most of the reported examples containing mixed $N, O$ ligands. Hydroxylamines were reported inactive in this reaction in $2006,{ }^{63}$ however, histidine derivatives such as $\mathbf{3 4}$ accelerate $\mathrm{CuAAC}$ in a similar rate than wellestablished DIPEA or $\mathrm{NEt}_{3}$ (Scheme 7). ${ }^{64}$ Neither imidazole, nor $\mathrm{N}$-methylimidazole displayed any activating properties in these reactions, proving the importance of the aminoacid moiety. In particular, when histidine-containing peptides were used as starting materials they could selfactivate the cycloaddition reaction due to their strong coordination to the copper center, which actually is most often regarded as a drawback for the use of peptides in CuAAC. Still, these reactions, carried out under inert atmosphere, required a stoichiometric quantity (or an excess) of $\mathrm{CuI}$, which led to the important formation of 5-iodotriazoles as by-products.

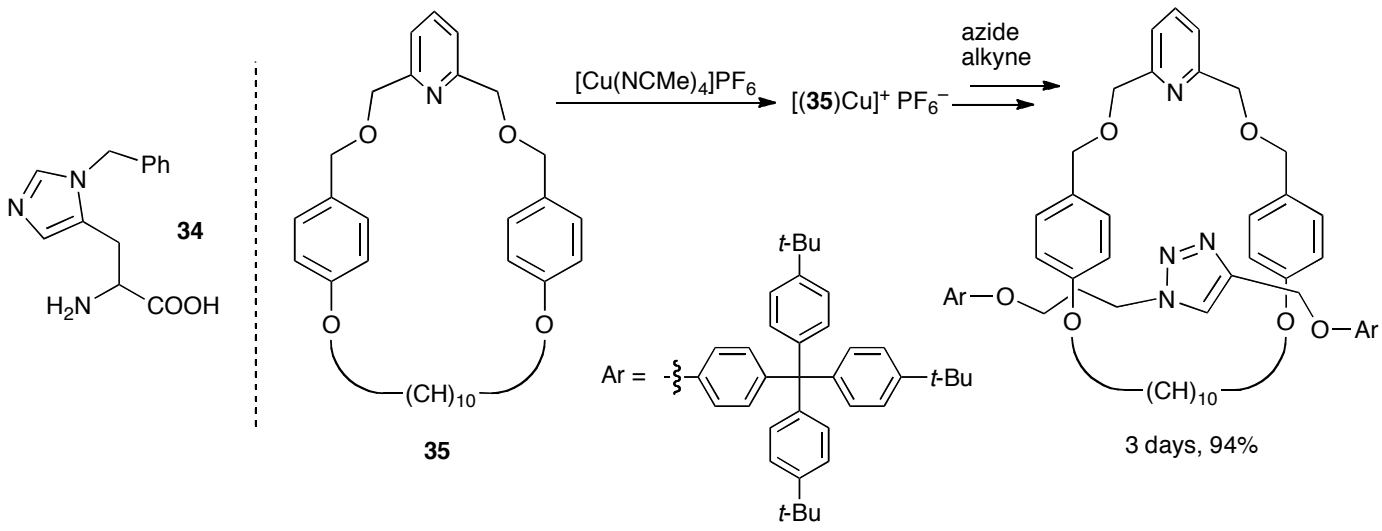

Scheme 7. O-Containing ligands in CuAAC.

Also, a $O, N, O$-macrocycle actively participated in the preparation of interlocked rotaxanes. ${ }^{65}$ In a first stage, macrocycle 35 was reacted with equimolar $\left[\mathrm{Cu}(\mathrm{NCMe})_{4}\right] \mathrm{PF}_{6}$ to yield $\left[(\mathrm{ONO}) \mathrm{Cu}^{\mathrm{I}}\right]$ species, active in the formation of triazoles from the corresponding azides and alkynes (Scheme 7). Since the copper species remained sequestered in the resulting rotaxane no turn over was observed under these conditions. Remarkably, upon simple addition of competing pyridine, the reaction could be run with only $4 \mathrm{~mol} \%[\mathrm{Cu}]$.

Copper(I) acetate $\mathbf{3 6}$ has been reported to be a highly efficient catalyst for $\mathrm{CuAAC}$ in the absence of any other ligand or additive. ${ }^{66}$ Its superiority when compared to other copper(I) salts such as 
$\mathrm{CuCl}, \mathrm{CuBr}$ or $\mathrm{CuCN}$ was suggested to be due to its dinuclear nature, very similar to the alkynyl copper(I) intermediate 37 proposed by DFT studies (Figure 7). ${ }^{67}$
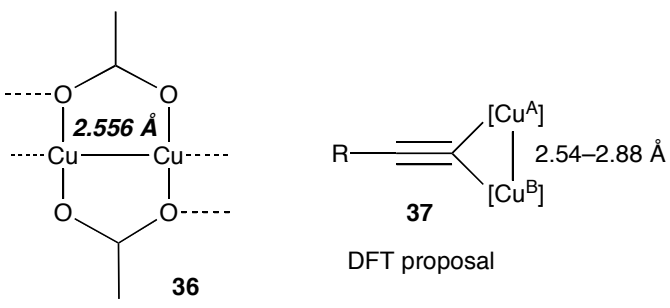

Figure 7. Dinuclear copper(I) complexes.

A number of triazoles could be prepared in excellent yields using 1-0.5 mol \% 37 (loadings of only $0.01 \mathrm{~mol} \%$ were also showed efficient for a model reaction) at room temperature under neat conditions. Regrettably, the reaction products were purified on silica gel. Similarly, carboxylic acid, and benzoic acid in particular, greatly accelerated the cycloaddition reaction when added to a mixture containing copper(II) sulphate and sodium ascorbate. ${ }^{68}$

\subsection{Sulfur Ligands}

Sulfur-based ligands might not be the most popular ones, but they have already displayed a very promising catalytic activity in $\mathrm{CuAAC}$. $\mathrm{CuBr} \cdot \mathrm{SMe}_{2}$, being commercially available, was first used simply as a copper(I) source soluble in organic solvents, similarly to $\left[\mathrm{Cu}(\mathrm{NCMe})_{4}\right] \mathrm{PF}_{6} .{ }^{69}$ The first methodological study reported for these ligands was reported by $\mathrm{Fu}$ and co-workers in 2008 . Thiophene, tetrahydrothiophene and 1,2-dithiophenylethane ligands were tested among others to find that when using water as reaction media the best results were obtained with thioanisole (Scheme 8). ${ }^{70}$ Excellent yields were obtained in short reaction times at room temperature, however, very high copper loadings and purification on silica gel were required for this catalytic system.

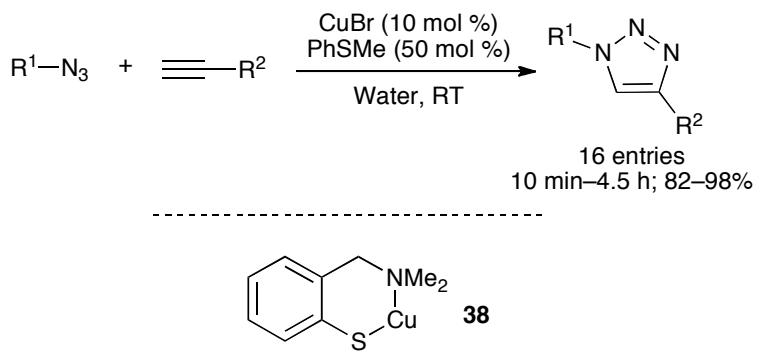

Scheme 8. $S$-Ligand/copper(I)-mediated CuAAC.

It is important to note that in this study DMSO was also screened, although its influence on the catalytic outcome was mitigated. This is of importance because some mechanistic studies on the ligand-free CuAAC reaction have been performed in DMSO/water mixtures, where copper ligation probably occurs. ${ }^{71}$ 
A previously known (aminoarenethiolato)copper complex 38 (Scheme 8) has also been investigated for this reaction. In this case, $1 \mathrm{~mol} \%$ of $\mathbf{3 8}$ was generally enough for ensuring high conversions in DCM or MeCN. ${ }^{72}$ This catalyst requires anhydrous solvents and purification on silica gel. However, it could be used for the formation of dendrimers and immobilization of pincer catalysts on azide-functionalized silica (in inert atmosphere though), ${ }^{73}$ two particularly challenging applications due to the risk of copper species remaining trapped in the reaction products.

\section{Ligated Copper(I) Species for Broader Reaction Scope}

\subsection{Reactions of In Situ Generated Azides and Terminal Alkynes}

Although organic azides are generally safe and stable towards water and oxygen (a must in Click chemistry), ${ }^{74}$ those of low molecular weight can be particularly dangerous and difficult to handle. ${ }^{75}$ In consequence, a number of methodologies have been developed in the literature to avoid the handling and isolation of organic azides for [3+2] cycloadditions.

An early report showed that 1,4-disubstituted triazoles could be prepared via a three-component reaction (organic bromide, $\mathrm{NaN}_{3}$ and an alkyne) upon heating at $75-125^{\circ} \mathrm{C}$ under $\mathrm{MW}$ irradiation in the presence of 1 equivalent of copper. ${ }^{76}$ Even though such drastic conditions might not be required in most cases, ${ }^{77}$ this approach still has a large leeway for improvement.

A number of ligated copper(I) species have been applied to the cycloaddition of in situ generated azides from the corresponding halogenated precursors (Scheme 9). NHC complex 30 was the first pre-formed catalyst reported for this transformation. ${ }^{52}$ Excellent yields were obtained after short reaction times, and no purification on silica gel was required. The copper loading used, however, was rather high. Triazole complex 17 was active for the same transformation with only $1 \mathrm{~mol} \%$, although in this case, heating and chromatography purification were needed. ${ }^{34}$ Benzylthio complex 39 was used in a mixture $\mathrm{MeCN} /$ water at room temperature. ${ }^{78} 1 \mathrm{~mol} \%[\mathrm{Cu}]$ was enough to ensuring a high yield, although only a model reaction was investigated and purification on silica gel was required. In this case, how the active copper(I) species are formed remains uncertain. Even if acetonitrile is known to promote such reduction, ${ }^{79}$ the reactions also proceeded in pure water. 


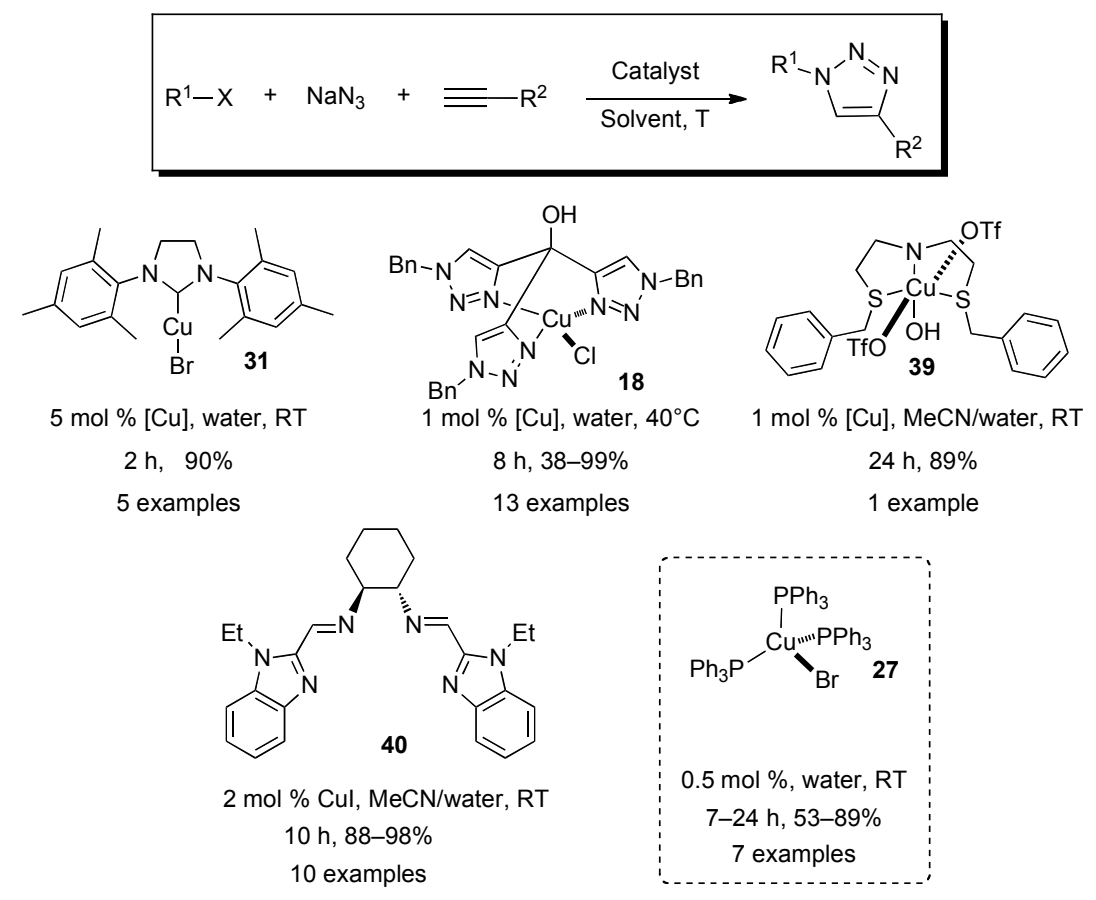

Scheme 9. Copper(I) complexes for a three-component reaction.

Nitrogen tetradentate ligand $\mathbf{4 0}$ was also used in this transformation in combination with $\mathrm{CuI}$ (Scheme 9). ${ }^{80}$ In the presence of $2 \mathrm{~mol} \%[\mathrm{Cu}]$, the corresponding triazoles could be prepared in high yields after $10 \mathrm{~h}$ of reaction at room temperature. Regrettably, again the reaction products had to be purified on silica gel. Probably, the most Click-suitable catalyst reported so far for this threecomponent reaction is phosphine complex $26 .{ }^{49}$ Only $0.5 \mathrm{~mol} \%[\mathrm{Cu}]$ was enough to ensure good yields at room temperature for a number of triazoles with no further purification required.

Silica supported catalyst 41 displayed a moderate activity in hot EtOH (Figure 8). ${ }^{81} 5 \mathrm{~mol} \%[\mathrm{Cu}]$ were used, although this catalyst could be recycled 8 times without a significant loss of reactivity. Nevertheless, reactions were carried out in a nitrogen atmosphere and the resulting products were purified by column chromatography.
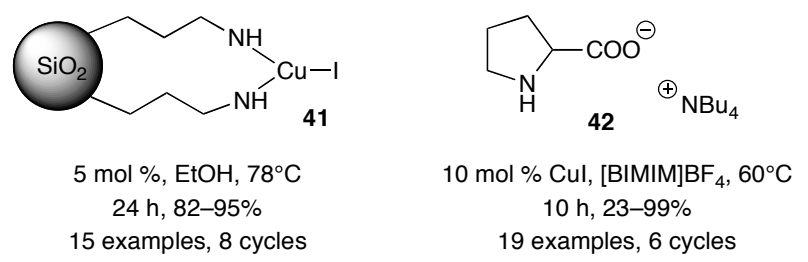

Figure 8. Recyclable catalysts for a three-component reaction.

A proline-containing ionic liquid $\mathbf{4 2}$ was also used in this transformation at $60^{\circ} \mathrm{C}$ under nitrogen atmosphere. ${ }^{82}$ The obtained products were purified by column chromatography and even if the copper loadings used were high $(10 \mathrm{~mol} \%)$, this catalytic system could be reused in six consecutive runs without significant lost of activity. The nature of the active species in this case remains undetermined. Even if the proline counterpart was suggested to coordinate the copper(I) center during the cycloaddition process, it is plausible that its presence is more important in the 
formation of aromatic azides from the corresponding halides. ${ }^{83}$ Also, the role of BIMIM (1-butyl3-imidazolium) as reaction media might not be trivial. ${ }^{84}$

\subsection{Reactions of Electron-Deficient Azides and Alkynes}

Sulfonyl azides have been thoroughly studied due to their rich reactivity in the presence of copper(I) acetylides. The outcome of their reactions can indeed be finely tuned with different ligands/additives in the reaction mixtures. "Regular" $N$-sulfonyl-1,2,3-triazoles can be obtained using a combination $\mathrm{CuI} / \mathrm{lutidine},{ }^{85} \mathrm{CuBr} / \mathrm{PhSMe},{ }^{86}$ or complex 43 (Scheme 10). ${ }^{87}$ It is important to note that in the absence of ligands only traces of the cycloaddition product could be detected and while no precautions to exclude oxygen were required in all these systems, only $\mathbf{4 3}$ afforded pure triazoles without purification on silica gel.

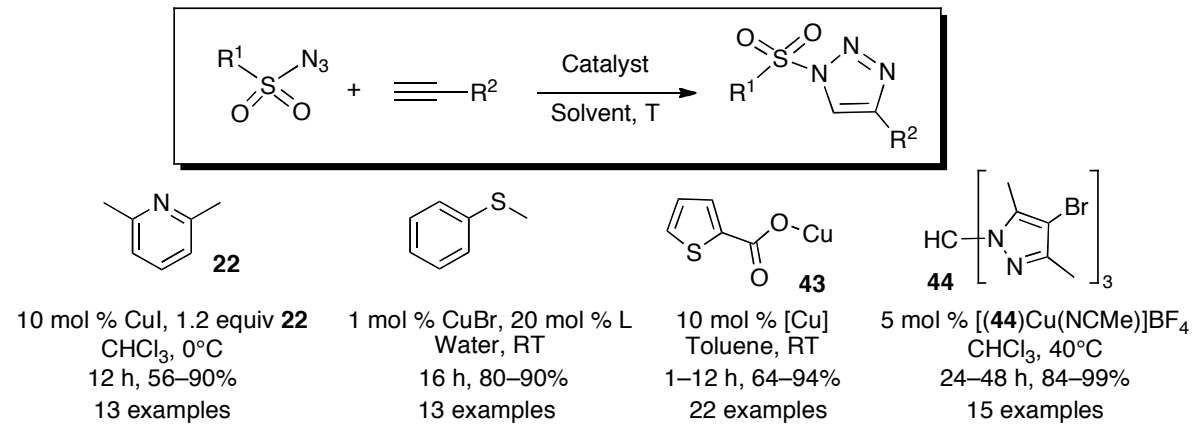

Scheme 10. Preparation of $N$-sulfonyltriazoles.

Also, $5 \mathrm{~mol} \%$ of $[(44) \mathrm{Cu}(\mathrm{NCMe})] \mathrm{BF}_{4}$ complex, where 44 is a trispyrazolylmethane ligand, produced the expected $\mathrm{N}$-sulfonyl-1,2,3-triazoles in warm chloroform, but again they had to be purified by column chromatography. ${ }^{88}$

Alternatively, sulfonyl azides can generate amidines when reacted with alkynes and amines in the presence of $10 \mathrm{~mol} \mathrm{\%}$ of $\mathrm{CuI}$ at room temperature. ${ }^{89}$ Clarification of the possible different roles of the amine in this particular case is still needed, particularly since amides were obtained instead when similar azides and alkynes were treated with $\mathrm{CuI} / \mathrm{NEt}_{3}$ in the presence of water at room temperature (Scheme 11). Whereas high catalyst loadings $(20 \mathrm{~mol} \%)$ were used when the reactions were carried out in chloroform, ${ }^{90}$ only 2 mol \% were enough when using pure water as solvent. ${ }^{91}$ Very similar results were obtained with a combination $\left[\mathrm{Cu}(\mathrm{NCMe})_{4}\right] \mathrm{PF}_{6} / \mathrm{TBTA}^{12}$ in a mixture $t-\mathrm{BuOH} /$ water at room temperature. ${ }^{92}$

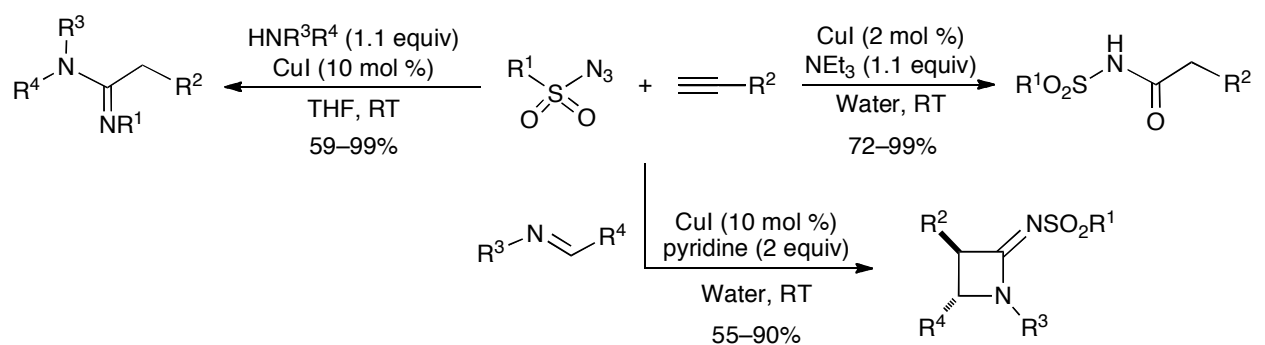


Scheme 11. Further reactivity of sulfonyl azides.

Alternatively, when the reactions were carried out in the presence of pyridine, azetidimine derivatives were isolated instead. ${ }^{93}$ From the original observation, it was supposed that such derivatives were the product of the dimerization of one of the catalytic intermediates, namely a ketenimine, thus the presence of an imine in the reaction media led to a very modular access to azatidin-2-imines under very mild conditions. Furthermore, the reaction was highly selective and the trans isomer was in most cases the only isolated product. Interestingly, TBTA 12 also increased the rate of this reaction, but at the same time, it altered the stereoselectivity and the cis isomer was then obtained as the major product.

This diverse reactivity is intrinsically related to the instability of the corresponding coppertriazolide intermediate, in which a $\mathrm{N}-\mathrm{N}$ bond cleavage is particularly favored. A mechanistic rationale for the formation of the aforementioned products is presented in Scheme 12. The standard cycloaddition catalytic cycle of cycloaddition reaction of azides and alkynes would generate 1-sulfonyltriazolyl copper species, which would lead to the corresponding triazole upon protonation. Alternatively, a ring opening process appeared to have a much lower energetic barrier, resulting in ketimines species could then be trapped with different nucleophiles, such as amines, imines, and water.

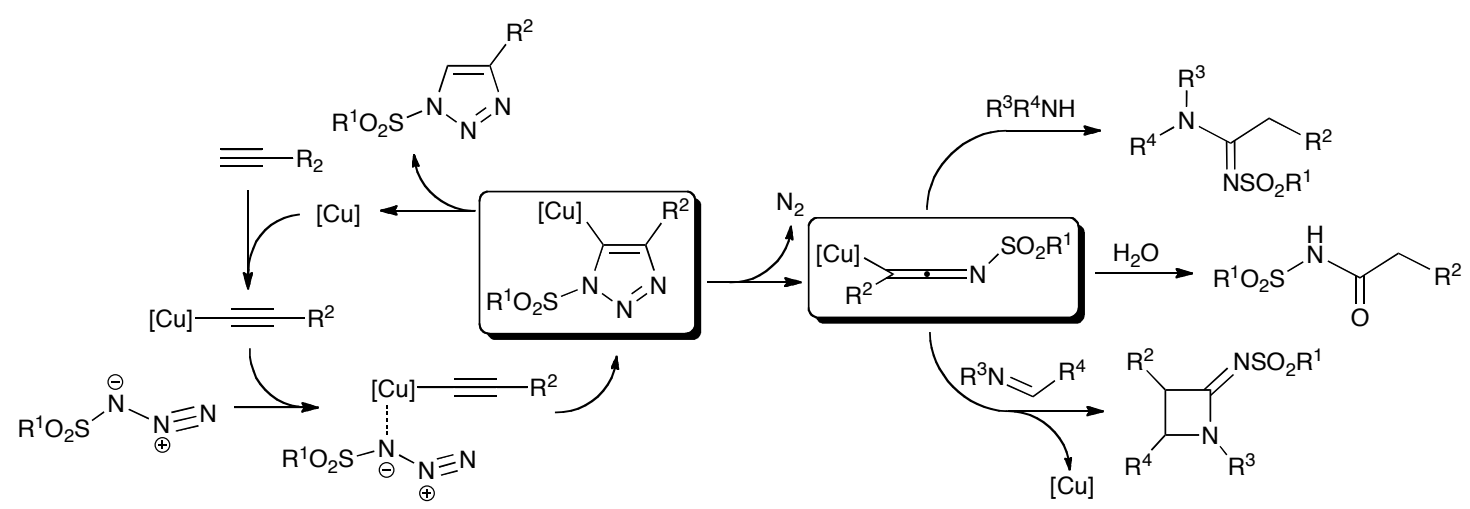

Scheme 12. Postulated mechanisms for reactions with sulfonyl azides.

\subsection{Reactions of Organic Azides and Internal Alkynes}

Since the first step of the widely accepted mechanism for CuAAC is the formation of a copperacetylide derivative (Scheme 2), disubstituted alkynes are considered inert under such conditions. Moreover, DFT calculations showed that a hypothetical activation toward cycloaddition via $\pi$ coordination of the copper(I) center to the alkyne has a higher energetic barrier than the uncatalyzed process. ${ }^{6}$ Nevertheless, catalysts $\mathbf{3 0}$ and $\mathbf{5}$ can mediate the reaction of benzyl azides and 3-hexyne (Scheme 13). ${ }^{52,17}$ Even though these reactions are not ideal (and only one alkyne was studied), they proved that alternative activation pathways are possible for copper-catalyzed 
cycloadditions. It is important to note that in the presence of $\mathrm{CuBr}$ under similar conditions, only sluggish reactions were observed, which proves the crucial role of the ligands in this reaction.

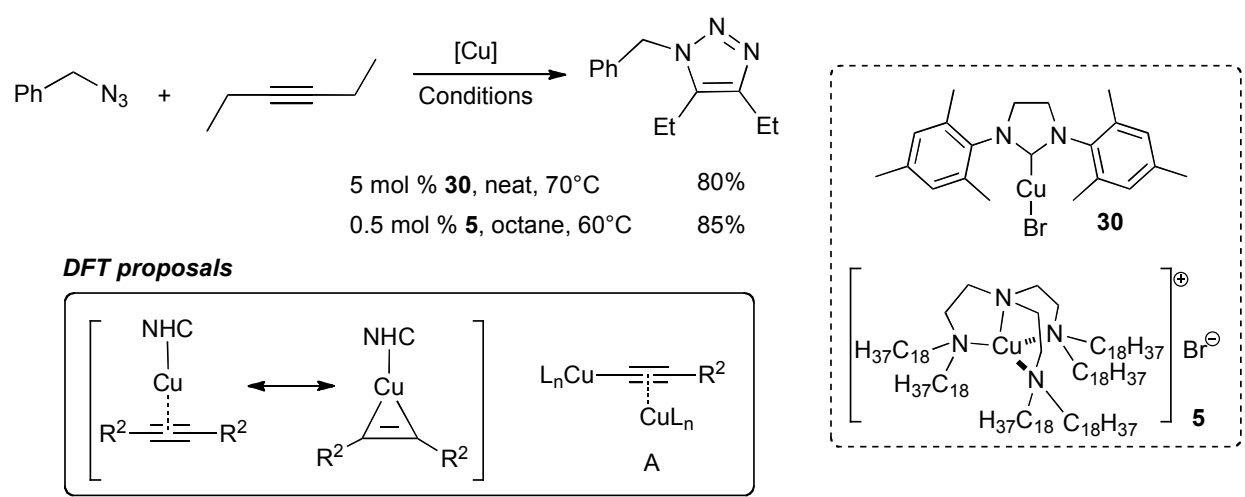

Scheme 13. Copper-catalyzed cycloaddition of 3-hexyne.

In the case of 30, DFT calculations pointed towards a $\pi$-coordination of the alkyne to the copper center to be favored by the presence of the SIMes ligand, even though the $\pi$-bonding/backbonding contribution to the $\mathrm{Cu}$-alkyne interaction was similar in its absence. It is important to note that later theoretical studies suggested for terminal alkynes a significant activation of copper-acetylide intermediated via $\pi$-coordination of a second center (Scheme 13, A). ${ }^{67 \mathrm{~b}}$

Another family of internal alkynes, iodo-alkynes, were also found suitable substrates for the preparation of 1,4,5-trisubstituted triazoles (Scheme 14). In this case too, the use of a coordinating ligand is essential for the reaction to take place. A combination of TTTA 15 and CuI (5 mol \%) provided good to excellent yields at room temperature after short reaction times (Scheme 14). ${ }^{94}$ Pre-formed catalyst $\mathbf{4 5}$ led to similarly notable results with lower copper loading of $2 \mathrm{~mol} \%$ in aqueous media. ${ }^{95}$ Remarkably, in both cases, filtration or extraction techniques yielded directly analytically pure products.

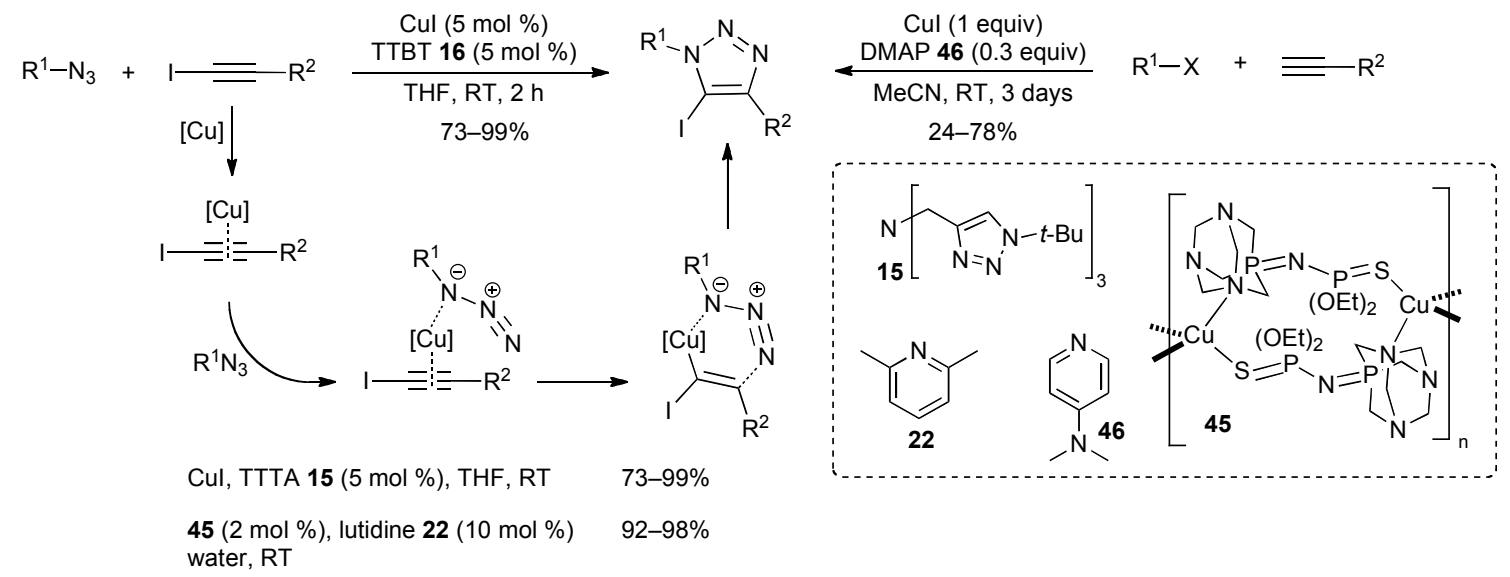

Scheme 14. Preparation of 1,4-disubstituted-5-iodotriazoles.

Here again, the $\pi$-activation of the alkyne was proposed, which was supported by the absence of $5 \mathrm{H}$-triazoles in the crude mixture. However, in these reactions, a sequence oxidative addition/cycloaddition/reductive elimination is also plausible. 
Alternatively, 5-iodotriazoles can be prepared from terminal alkynes in the presence of a stoichiometric amount of CuI and DMAP 46 (4-dimetylaminopyridine) as additive (no such reaction was observed with DIPEA or dimetylacetamide). ${ }^{96}$ Besides the use of CuI as iodide source, the main drawbacks of this approach are the long reaction times and the fluctuating yields.

\subsection{Functionalization of Triazolide Intermediates}

Under certain conditions, the copper-triazolide species can be trapped with an electrophile or with the starting alkyne (Scheme 15). DIPEA is a good additive for the former ${ }^{97}$ and here it does not only serve as a ligand and base for the copper-acetylide formation, but also as proton sponge for any acid coming from the electrophile. Despite the precaution taken, 'regular' 5-H-triazole derivatives were also obtained and stoichiometric amounts of copper salts were compulsory to ensure moderate to good reaction yields.

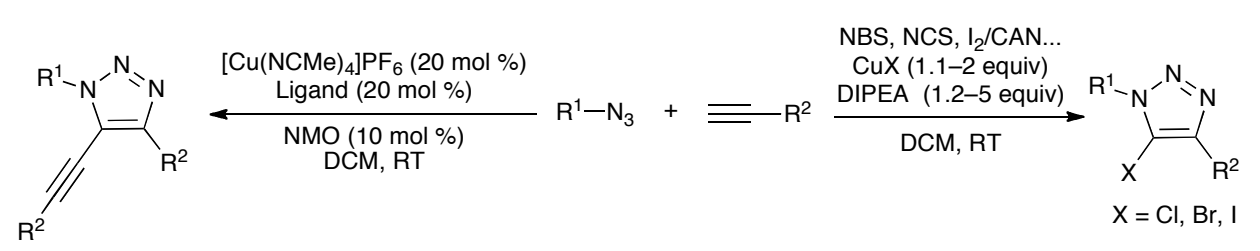

Scheme 15. Trapping of copper-triazolide species.

Diamine ligands have been shown to allow a similar trapping by the starting alkyne. ${ }^{63}$ The presence of an oxidant in the reaction mixture points towards the involvement of copper(II)/copper(III) species. Furthermore, whereas peralkylated ligands privileged the formation of disubstituted triazoles, ligands with $\mathrm{N}-\mathrm{H}$ bonds favored trisubstituted products. Overall, up to $68 \%$ of trisubstituted triazoles could be isolated after column chromatography, along with the corresponding 1,4-disubstituted analogues.

Finally, DIPEA has also been applied to the selective formation of bis-triazoles either from dialkynes ${ }^{98}$ or diazides, ${ }^{99}$ although once again, the actual role of the additive has not been particularly investigated.

\section{Conclusions and Outlook}

The huge and sudden popularity acquired by CuAAC has few precedents in literature. Even if the use of ligated copper derivatives has played an important role in its development, this cycloaddition reaction remains a victim of its own success and when comparing to its numerous applications, only marginal efforts have been focused on the discovery of improved catalytic systems. This gap is more evident for nitrogen-based ligands, whereas mainly methodological studies have been carried out with NHC and sulfur-based ligands, despite the impressive reactivity they have displayed so far. 
It is noticeable that many, if not most, of the applications reported so far do not completely meet the Click criteria. Without dismissing their importance (since this might be due to the inherent sensitive nature of the starting materials, or the final products), it is anticipated, that a better knowledge of the effect of ligands in this reaction (notably on the mechanism and the rate limiting step) would allow for a higher number of applications to be run under strict Click conditions, with all the experimental, economical and environmental benefits this would bring.

Acknowledgements: The author gratefully acknowledges Imperial College London for provision of an Imperial College Junior Research Fellowship.

\section{References and Notes}

${ }^{1}$ H. C. Kolb, M. G. Finn and K. B. Sharpless, Angew. Chem., Int. Ed., 2001, 40, 2004-2021.

${ }^{2}$ R. Huisgen, Pure Appl. Chem., 1989, 61, 613-628.

${ }^{3}$ G. L'abbé, Bull. Soc. Chim. Belges, 1984, 93, 579-592.

${ }^{4}$ V. V. Rostovtsev, L. G. Green, V. V. Fokin and K. B. Sharpless, Angew. Chem., Int. Ed., 2002, 41, 2596-2599.

${ }^{5}$ C. W. Tornøe, C. Christensen and M. Meldal, J. Org. Chem., 2002, 67, 3057-3064.

${ }^{6}$ F. Himo, T. Lovell, R. Hilgraf, V. V. Rostovtsev, L. Noodleman, K. B. Sharpless and V. V. Fokin, J. Am. Chem. Soc., 2005, 127, 210-216.

${ }^{7}$ (a) V. D. Bock, H. Hiemstra and J. H. van Maarseveen, Eur. J. Org. Chem., 2005, 51-68; (b) B. R. Buckley, S. E. Dann and H. Heaney, Chem.-Eur. J., 2010, 16, 6278-6284.

8 J. M. Baskin and C. R. Bertozzi, Aldrichimica Acta, 2010, 43, 15-23.

9 1,5-Disubstituted triazoles can be regioselectively prepared with ruthenium catalysis, although under non-Click conditions: (a) B. C. Boren, S. Narayan, L. K. Rasmussen, L. Zhang, H. Zhao, Z. Lin, G. Jia and V. V. Fokin, J. Am. Chem. Soc., 2008, 130, 8923-8930. For a recent metal-free preparation, see: (b) S. W. Kwok, J. R. Fotsing, R. J. Fraser, V. O. Rodionov and V. V. Fokin, Org. Lett., 2010, 12, 4217-4219.

${ }^{10}$ B. Wieczorek, B. Lemcke, H. P. Dijkstra, M. R. Egmond, R. J. M. K. Gebbink and G. van Koten, Eur. J. Inorg. Chem., 2010, 1929-1938; (b) B. Trastoy, M. E. Perez-Ojeda, R. Sastre and J. L. Chiara, Chem.-Eur. J., 2010, 16, 3833-3841.

11 (a) Special issue on Click chemistry: Chem. Soc. Rev., 2010, 39, 1221-1408; (b) For a comprehensive review, see: M. Meldal and C. W. Tornøe, Chem. Rev., 2008, 108, 2952-3015; (c) W. H. Struthers, T. L. Mindt and R. Schibli, Dalton Trans., 2010, 39, 675-696; (d) M. Glaser and 
E. G. Robins, J. Labelled Compd. Radiopharm., 2009, 52, 407-414; (e) P. L. Golas, and M. Meldal, Macromol. Rapid Commun., 2008, 29, 1016-1051; (f) C. Najera and J. M. Sansano, Org. Biomol. Chem., 2009, 7, 4567-4581; (g) G. Franc and A. Kakkar, Chem. Commun., 2008, 52675276; (h) W. H. Binder and R. Sachsenhofer, Macromol. Rapid Commun., 2007, 28, 15-54; (i) J. F. Lutz, Angew. Chem., Int. Ed., 2007, 46, 1018-1025; (j) A. Dondoni, Chem.-Asian J., 2007, 2, 700-708.

12 (a) Y. M. Wu, J. Deng, X. Fang and Q. Y. Chen, J. Fluorine Chem., 2004, 125, 1415-1423; (b) Z. Y. Yan, Y. B. Zhao, M. J. Fan, W. M. Liu and Y. M. Liang, Tetrahedron, 2005, 61, 9331-9337. For 'on water' reactions, see: (c) S. Narayan, J. Muldoon, M. G. Finn, V. V. Fokin, H. C. Kolb and K. B. Sharpless, K.B., Angew. Chem., Int. Ed., 2005, 44, 3275-3279; (d) R. N. Butler and A. G. Coyne, Chem. Rev., 2010, 110, 6302-6337.

${ }^{13}$ T. Hasegawa, M. Umeda, M. Numata, T. Fujisawa, S. Haraguchi, K. Sakurai and S. Shinkai, Chem. Lett., 2006, 35, 82-83; (b) K. A. Kalesh, K. Liu, S. Q. Yao, Org. Biomol. Chem., 2009, 7, 5129-5136.

${ }^{14}$ S. Hartwig and S. Hecht, Macromolecules, 2010, 43, 242-248.

15 A. Baron, Y. Bleriot, M. Sollogoub and B. Vauzeilles, Org. Biomol. Chem., 2008, 6, 18981901.

${ }^{16}$ L. Bonami, W. Van Camp, D. Van Rijckegem and F. E. Du Prez, Macromol. Rapid Commun., 2009, 30, 34-38.

${ }^{17}$ N. Candelon, D. Lastécouères, A. K. Diallo, J. R. Aranzaes, D. Astruc and J. M. Vincent, Chem. Commun., 2008, 741-743.

${ }^{18}$ B. Trastoy, M. E. Pérez-Ojeda, R. Sastre and J. L. Chiara, Chem.-Eur. J., 2010, 16, 3833-3841. 19 (a) A. J. Dirks, S. S. van Berkel, H. I. V. Amatdjais-Groenen, F. P. J. T. Rutjes, J. J. L. M. Cornelissen and R. J. M. Nolte, Soft Matter, 2009, 5, 1692-1704; (b) J. Kulis, C. A. Bell, A. S. Micallef, Z. F. Jia and M. J. Monteiro, Macromolecules, 2009, 42, 8218-8227.

${ }^{20}$ G. Mantovani, V. Ladmiral, L. Tao and D. M. Haddleton, Chem. Commun., 2005, 2089-2091.

${ }^{21}$ J. Geng, J. Lindqvist, G. Mantovani and D. M. Haddleton, Angew. Chem., Int. Ed., 2008, 47, 4180-4183.

22 J. C. Meng, V. V. Fokin and M. G. Finn, Tetrahedron Lett., 2005, 46, 4543-4546.

${ }^{23}$ K. Asano and S. Matsubara, Org. Lett., 2010, 12, 4988-4991.

${ }^{24}$ For a few selected examples, see: (a) J. A. Opsteen and J. C. M. van Hest, Chem. Commun., 2005, 57-59; (b) M. Urien, H. Erothu, E. Cloutet, R. C. Hiorns, L. Vignau and H. Cramail, 
Macromolecules, 2008, 41, 7033-7040; (c) Z. Guo, L. Liang, J. J. Liang, Y. F. Ma, X. Y. Yang, D. M. Ren, Y. S. Chen and J. Y. Zheng, J. Nanopart. Res., 2008, 10, 1077-1083.

25 A. Coelho, P. Diz, O. Caamaño and E. Sotelo, Adv. Synth. Catal., 2010, 352, 1179-1192.

${ }^{26}$ (a) Q. Wang, T. R. Chan, R. Hilgraf, V. V. Fokin, K. B. Sharpless and M. G. Finn, J. Am. Chem. Soc., 2003, 125, 3192-3193; (b) A. E. Speers, G. C. Adam and B. F. Cravatt, J. Am. Chem. Soc., 2003, 125, 4686-4687; (c) A. J. Link and D. A. Tirrell, J. Am. Chem. Soc., 2003, 125, $11164-$ 11165.

${ }^{27}$ T. R. Chan, R. Hilgraf, K. B. Sharpless and V. V. Fokin, Org. Lett., 2004, 6, 2853-2855.

${ }^{28}$ T. R. Chan and V. V. Fokin, QSAR Comb. Sci., 2007, 26, 1274-1279.

${ }^{29}$ For examples on well-defined $1 H$-[1,2,3]-triazole-copper(I) complexes, see: (a) J. Xiang, Y.-G. Yi and P. Mei, Inorg. Chem. Commun., 2007, 10, 1168-1171; (b) G. F. Manbeck, W. W. Brennessel, C. M. Evans and R. Eisenberg, Inorg. Chem., 2010, 49, 2834-2843.

${ }^{30}$ C. M. Santos, A. Kumar, W. Zhang and C. Z. Cai, Chem. Commun., 2009, 2854-2856.

${ }^{31}$ A. H. El-Sagheer and T. Brown, J. Am. Chem. Soc., 2009, 131, 3958-3964.

${ }^{32}$ V. Hong, S. Presolski, C. Ma and M. G. Finn, Angew. Chem., Int. Ed., 2009, 48, 9879-9883.

${ }^{33}$ P. S. Donnelly, S. D. Zanatta, S. C. Zammit, J. M. White and S. J. Williams, Chem. Commun., 2008, 2459-2461.

${ }^{34}$ S. Özçubukçu, E. Ozkal, C. Jimeno and M. A. Pericàs, Org. Lett., 2009, 11, 4680-4683.

35 (a) V. O. Rodionov, S. I. Presolski, S. Gardinier, Y. H. Lim and M. G. Finn, J. Am. Chem. Soc., 2007, 129, 12696-12704; (b) V. O. Rodionov, S. I. Presolski, D. D. Diaz, V. V. Fokin and M. G. Finn, J. Am. Chem. Soc., 2007, 129, 12705-12712; (c) S. I. Presolski, V. Hong, S.-H. Cho and M. G. Finn, J. Am. Chem. Soc., 2010, 132, 14570-14576.

${ }^{36}$ P. Bertrand and J. P. Gesson, J. Org. Chem., 2007, 72, 3596-3599.

${ }^{37}$ V. R. Sirivolu, P. Chittepu and F. Seela, ChemBioChem, 2008, 9, 2305-2316.

38 (a) D. D. Diaz, K. Rajagopal, E. Strable, J. Schneider and M. G. Finn, J. Am. Chem. Soc., 2006, 128, 6056-6057; (b) B. Peschke, M. Zundel, S. Bak, T. R. Clausen, N. Blume, A. Pedersen, F. Zaragoza and K. Madsen, Bioorg. Med. Chem., 2007, 15, 4382-4395;.

${ }^{39}$ W. G. Lewis, F. G. Magallon, V. V. Fokin and M. G. Finn, J. Am. Chem. Soc., 2004, 126, 91529153.

${ }^{40}$ S. Sen Gupta, J. Kuzelka, P. Singh, W. G. Lewis, M. Manchester and M. G. Finn, Bioconjugate Chem., 2005, 16, 1572-1579.

${ }^{41}$ M. Chtchigrovsky, A. Primo, P. Gonzalez, K. Molvinger, M. Robitzer, F. Quignard and F. Taran, Angew. Chem., Int. Ed., 2009, 48, 5916-5920. 
${ }^{42}$ G.-C. Kuang, H. A. Michaels, J. T. Simmons, R. J. Clark and L. Zhu, J. Org. Chem., 2010, 75, $6540-6548$.

${ }^{43}$ W. S. Brotherton, H. A. Michaels, J. T. Simmons, R. J. Clark, N. S. Delal and L. Zhu, Org. Lett., 2009, 11, 4954-4957.

${ }^{44}$ F. Pérez-Balderas, M. Ortega-Muñoz, J. Morales-Sanfrutos, F. Hernández-Mateo, F. G. CalvoFlores, J. A. Calvo-Asín, J. Isac-García and F. Santoyo-González, Org. Lett., 2003, 5, 1951-1954.

45 (a) L. Marmuse, S. A. Nepogodiev and R. A. Field, Org. Biomol. Chem., 2005, 3, 2225-2227;

(b) V. Ladmiral, G. Mantovani, G. J. Clarkson, S. Cauet, J. L. Irwin and D. M. Haddleton, J. Am. Chem. Soc., 2006, 128, 4823-4830; (c) T. Kato, A. Miyagawa, M. C. Z. Kasuya and K. Hatanaka, The Open Chemical and Biomedical Methods Journal, 2009, 2, 13-17; (d) B. Parrish and T. Emrick, Bioconjugate Chem., 2007, 18, 263-267.

${ }^{46}$ C. Papin, G. Doisneau and J. M. Beau, Chem.-Eur. J., 2009, 15, 53-57.

47 (a) J. Shen, R. Woodward, J. P. Kedenburg, X. W. Liu, M. Chen, L. Y. Fang, D. X. Sun, and P. G. Wang, J. Med. Chem., 2008, 51, 7417-7427; (b) A. Méndez-Ardoy, M. Gómez-García, C. Ortiz Mellet, N. Sevillano, M. D. Girón, R. Salto, F. Santoyo-González and J. M. García Fernández, Org. Biomol. Chem., 2009, 7, 2681-2684.

48 (a) N. Pietrzik, C. Schips and T. Ziegler, Synthesis, 2008, 519-526; (b) A. D. Ievins, X. F. Wang, A. O. Moughton, J. Skey and R. K. O'Reilly, Macromolecules, 2008, 41, 2998-3006; (c) A. J. Qin, J. W. Y. Lam, L. Tang, C. K. W. Jim, H. Zhao, J. Z. Sun and B. Z. Tang, Macromolecules, 2009, 42, 1421-1424.

${ }^{49}$ S. Lal, A. J. P. White and S. Díez-González, submitted for publication.

${ }^{50}$ Z. Gonda and Z. Novák, Dalton Trans., 2010, 39, 726-729.

${ }^{51}$ L. S. Campbell-Verduyn, L. Mirfeizi, R. A. Dierckx, P. H. Elsinga and B. L. Feringa, Chem. Commun., 2009, 2139-2141.

${ }^{52}$ S. Díez-González, A. Correa, L. Cavallo and S. P. Nolan, Chem.-Eur. J., 2006, 12, 7558-7564.

${ }^{53}$ S. Díez-González, E. C. Escudero-Adán, J. Benet-Buchholz, E. D. Stevens, A. M. Z. Slawin and S. P. Nolan, Dalton Trans, 2010, 39, 7595-7606.

${ }^{54}$ (a) G. M. Pawar, B. Bantu, J. Weckesser, S. Blechert, K. Wurst and M. R. Buchmeiser, Dalton Trans., 2009, 9043-9051. See also: (b) P. H. Li, L. Wang and Y. C. Zhang, Tetrahedron, 2008, 64, $10825-10830$.

55 (a) M. L.Teyssot, A. Chevry, M. Traikia, M. El-Ghozzi, D. Avignant and A. Gautier, Chem.Eur. J., 2009, 15, 6322-6326; (b) M. L. Teyssot, L. Nauton, J.-L. Canet, F. Cisnetti, A. Chevry and A. Gautier, Eur. J. Org. Chem., 2010, 3507-3515. 
${ }^{56}$ S. Díez-González, E. D. Stevens and S. P. Nolan, Chem. Commun., 2008, 4747-4749.

${ }^{57}$ M. Sèverac, L. Le Pleux, A. Scarpaci, E. Blart and F. Odobel, Tetrahedron Lett., 2007, 48, $6518-6522$.

58 J. Broggi, S. Díez-González, J. L. Petersen, S. Berteina-Raboin, S. P. Nolan and L. A. Agrofoglio, Synthesis, 2008, 141-148.

59 (a) A. Maisonial, P. Serafin, M. Traikia, E. Debiton, V. Thery, D. J. Aitken, P. Lemoine, B. Viossat and A. Gautier, Eur. J. Inorg. Chem., 2008, 298-305; (b) A. Chevry, M.-L. Teyssot, A. Maisonial, P. Lemoine, B. Viossat, M. Traïka, D. Aitken, G. Alves, L. Morel, L. Nauton and A. Gautier, Eur. J. Inorg. Chem., 2010, 3513-3519.

${ }^{60}$ C. Nolte, P. Mayer and B. F. Straub, Angew. Chem., Int. Ed., 2007, 46, 2101-2103.

${ }^{61}$ S. Díez-González and S. P. Nolan, Angew. Chem., Int. Ed., 2008, 47, 8881-8884.

62 (a) Y. B. Zhao, Z. Y. Yan and Y. M. Liang, Tetrahedron Lett., 2006, 47, 1545-1549; (b) A. Marra, A. Vecchi, C. Chiappe, B. Melai and A. Dondoni, J. Org. Chem., 2008, 73, 2458-2461; (c) H. Hagiwara, H. Sasaki, T. Hoshi and T. Suzuki, Synlett, 2009, 643-647.

${ }^{63}$ B. Gerard, J. Ryan, A. B. Beeler and J. A. Porco Jr., Tetrahedron, 2006, 62, 6405-6411.

${ }^{64}$ K. Tanaka, C. Kageyama and K. Fukase, Tetrahedron Lett., 2007, 48, 6475-6479.

65 (a) V. Aucagne, K. D. Hanni, D. A. Leigh, P. J. Lusby and D. B. Walker, J. Am. Chem. Soc., 2006, 128, 2186-2187; (b) V. Aucagne, J. Berna, J. D. Crowley, S. M. Goldup, K. D. Haenni, D. A. Leigh, P. J. Lusby, V. E. Ronaldson, A. M. Z. Slawin, A. Viterisi and D. B. Walker, J. Am. Chem. Soc., 2007, 129, 11950-11963.

${ }^{66}$ C. Shai, G. Cheng, D. Su, J. Xu, X. Wang and Y. Hu, Adv. Synth. Catal., 2010, 352, 1587-1592. See also ref. 50.

67 (a) B. F. Straub, Chem. Commun., 2007, 3868-3870; (b) M. Ahlquist and V. V. Fokin, Organometallics, 2007, 26, 4389-4391.

${ }^{68}$ C. Shao, X. Wang, J. Xu, J. Zhao, Q. Zhang and Y. Hu, J. Org. Chem., 2010, 75, 7002-7005.

${ }^{69}$ (a) Y. Liu, D. D. Diaz, A. A. Accurso, K. B. Sharpless, V. V. Fokin and M. G. Finn, J. Polym. Sci., Part A: Polym. Chem., 2007, 45, , 5182-5189; (b) H. Isobe, T. Fujino, N. Yamazaki, M. Guillot-Nieckowski and E. Nakamura, Org. Lett., 2008, 10, 3729-3732.

${ }^{70}$ F. Wang, H. Fu, Y. Y. Jiang and Y. F. Zhao, Green Chem., 2008, 10, 452-456.

${ }^{71}$ V. O. Rodionov, V. V. Fokin and M. G. Finn, Angew. Chem., Int. Edit., 2005, 44, 2210-2215. See also ref. $35 \mathrm{c}$.

${ }^{72}$ P. Fabbrizzi, S. Cicchi, A. Brandi, E. Sperotto and G. van Koten, Eur. J. Org. Chem., 2009, 5423-5430. 
${ }^{73}$ A. R. McDonald, H. P. Dijkstra, B. M. J. M. Suijkerbuijk, G. P. M. van Klink and G. van Koten, Organometallics, 2009, 28, 4689-4699.

${ }^{74}$ (a) S. Bréase, C. Gil, K. Knepper and V. Zimmermann, Angew. Chem., Int. Ed., 2005, 44, 51885240; (b) E. Saxon and C. R. Bertozzi, Science, 2000, 287, 2007-2010.

${ }^{75}$ E. F. V. Scriven and K. Turnbull, Chem. Rev., 1988, 88, 297-368.

${ }^{76}$ P. Appukkuttan, W. Dehaen, V. V. Fokin and E. Van der Eycken, Org. Lett., 2004, 6, 42234225 .

${ }^{77}$ K. Kacprzak, Synlett, 2005, 943-946.

${ }^{78}$ S.-Q. Bai, L. Koh and T. S. A. Hor, Inorg. Chem., 2009, 48, 1207-1213.

${ }^{79}$ B. Kratochvil, D. A. Zatko and R. Markuszewski, Anal. Chem., 1966, 38, 770-772.

${ }^{80}$ F. Li and T. S. A. Hor, Chem.-Eur. J., 2009, 15, 10585-10592.

${ }^{81}$ T. Miao, L. Wang, Synthesis, 2008, 363-368.

82 J. C. Yan and L. Wang, Synthesis, 2010, 447-452.

${ }^{83}$ W. Zhu and D. Ma, Chem. Commun., 2004, 888-889.

${ }^{84}$ For another example of reaction in BIMIM, see: Y.-B. Zhao, Z.-Y. Yan and Y.-M. Liang, Tetrahedron Lett., 2006, 47, 1545-1549.

${ }^{85}$ E. J. Yoo, M. Ahlquist, S. H. Kim, I. Bae, V. V. Fokin, K. B. Sharpless and S. Chang, Angew. Chem., Int. Ed., 2007, 46, 1730-1733.

${ }^{86}$ F. Wang, H. Fu, Y. Y. Jiang, Y. F. Zhao, Adv. Synth. Catal., 2008, 350, 1830-1834.

${ }^{87}$ J. Raushel and V. V. Fokin, Org. Lett., 2010, 12, 4952-4955.

${ }^{88}$ I. Cano, M. C. Nicasio and P. J. Perez, Org. Biomol. Chem., 2010, 8, 536-538.

${ }^{89}$ (a) I. Bae, H. Han and S. Chang, J. Am. Chem. Soc., 2005, 127, 2038-2039; (b) E. J. Yoo, M. Ahlquist, I. Bae, K. B. Sharpless, V. V. Fokin and S. Chang, J. Org. Chem., 2008, 73, 5520-5528. ${ }^{90}$ S. H. Cho, E. J. Yoo, L. Bae and S. Chang, J. Am. Chem. Soc., 2005, 127, 16046-16047.

${ }^{91}$ S. H. Cho and S. Chang, Angew. Chem., Int. Ed., 2007, 46, 1897-1900.

92 M. P. Cassidy, J. Raushel and V. V. Fokin, Angew. Chem., Int. Ed., 2006, 45, 3154-3157.

${ }^{93}$ M. Whiting, V. V. Fokin, Angew. Chem., Int. Ed., 2006, 45, 3157-3161.

${ }^{94}$ J. E. Hein, J. C. Tripp, L. B. Krasnova, K. B. Sharpless and V. V. Fokin, Angew. Chem., Int. Ed., 2009, 48, 8018-8021.

95 J. García-Álvarez, J. Díez and J. Gimeno, Green. Chem., 2010, 12, 2127-2130. This catalyst also promotes the reaction of azides and terminal alkynes with only $0.5 \mathrm{~mol} \%[\mathrm{Cu}]$ on water.

${ }^{96}$ N. W. Smith, B. P. Polenz, S. B. Johnson and S. V. Dzyuba, Tetrahedron Lett., 2010, 51, 550553. 
${ }^{97}$ V. Malnuit, M. Duca, A. Manout, K. Bougrin and R. Benhida, Synlett, 2009, 2123-2128.

98 J. M. Aizpurua, I. Azcune, R. M. Fratila, E. Balentova, M. Sagartzazu-Aizpurua and J. I. Miranda, Org. Lett., 2010, 12, 1584-1587.

${ }^{99}$ O. A. Oladeinde, S. Y. Hong, R. J. Holland, A. E. Maciag, L. K. Keefer, J. E. Saavedra and R. S. Nandurdikar, Org. Lett., 2010, 12, 4256-4259. 